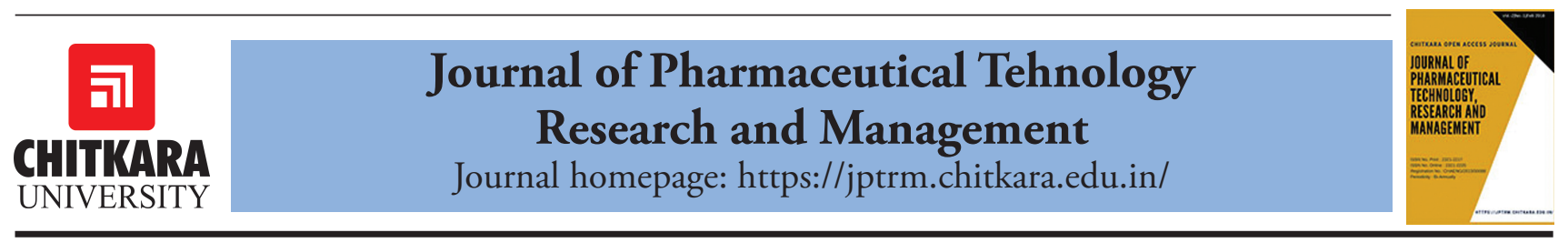

\title{
Design, Synthesis and Antidiabetic Activity of Novel Sulfamoyl Benzamide Derivatives as Glucokinase Activators
}

\author{
Ajmer Singh Grewal ${ }^{1}$, Kapil Sharma ${ }^{2}$, Sukhbir Singh ${ }^{1}$, Vikramjeet Singh $^{3}$, Deepti Pandita ${ }^{4}$ and Viney Lather ${ }^{5 *}$ \\ ${ }^{1}$ Chitkara College of Pharmacy, Chitkara University, Rajpura, 140401, Punjab, India \\ ${ }^{2}$ Jan Nayak Ch. Devi Lal Memorial College of Pharmacy, Sirsa, 125055, Haryana, India \\ ${ }^{3}$ Department of Pharmaceutical Sciences, GJUS\&T, Hisar, 125001, Haryana, India \\ ${ }^{4}$ Amity Institute of Molecular Medicine \& Stem Cell Research, Amity University, Noida, 201303, Uttar Pradesh, India \\ ${ }^{5}$ Amity Institute of Pharmacy, Amity University, Noida, 201303, Uttar Pradesh, India \\ *Email: vinnylather@gmail.com
}

\section{ARTICLE INFORMATION}

Received: June 09, 2018

Revised: Aug. 12, 2018

Accepted: Oct. 17, 2018

Published online: Nov. 2, 2018

Keywords:

Antidiabetic activity, Benzamides, Diabetes mellitus, Glucokinase, GK activators, Molecular Docking.

DOI : $10.15415 /$ jptrm.2018.62008

\begin{abstract}
The present work has been planned to design, synthesize and evaluate the antidiabetic potential of a series of sulfamoyl benzamide derivatives as potential glucokinase (GK) activators. A new series of sulfamoyl benzamide derivatives was synthesized starting from 3-nitrobenzoic acid and characterized. In silico docking studies were performed to determine the binding interactions for the best fit conformations in the allosteric site of GK enzyme. Based on the results of in silico studies, the selected molecules were tested for their antidiabetic activity in animal studies (alloxan induced diabetic animal model). Compound 7 exhibited highest antidiabetic activity in animal studies. The results of in vivo antidiabetic activity studies were found to be in parallel to that of docking studies. These newly synthesized sulfamoyl benzamide derivatives thus can be treated as the initial hits for the development of novel, safe, effective and orally bioavailable GK activators as therapeutic agents for the treatment of type 2 diabetes.
\end{abstract}

\section{Introduction}

Diabetes mellitus is a persistent metabolic disorder characterized by hyperglycemia with disturbed food metabolism, resulting from defect in either insulin action, insulin secretion or both, leading to vascular and tissue damage resulting in various other complications such as cataract, retinopathy, neuropathy, nephropathy, negative nitrogen balance, ketoacidosis, foot ulcers and cardiovascular disorders (Bastaki, 2005; Brownlee, 2001; Cade, 2008; Grewal et al., 2014). Type 2 diabetes (T2D) affecting more than $90 \%$ of all the diabetic patients, is a long-lasting malady of energy metabolism caused by reduced insulin action (Kohei et al., 2010; Olokoba et al., 2012). Even though a large number of options are available for the treatment of T2D, no single medicine is useful for achieving long lasting control of blood glucose levels in most of the T2D cases. Due to this reason, now-a-days physicians suggest treatment of T2D at an earlier stage with combination of antidiabetic agents. Overdose of antidiabetic drugs may cause severe hypoglycemia leading to severe toxic effects, and patients normally require urgent medical treatment (Olokoba et al., 2012). The scientific community is currently focusing on developing new, safe and clinically different antidiabetic agents that can be used as mono drug therapy with improved efficacy. Results from several recent studies, including emerging clinical data, have demonstrated that smallmolecule glucokinase (GK) activators may be able to fill this void (Pal, 2009; Pal, 2009a; Grewal et al., 2014).

GK is a cytoplasmic enzyme which catalyzes the conversion of glucose to glucose-6-phosphate in presence of ATP and controls the blood glucose levels in a safe and narrow physiological range in humans. GK is predominantly expressed in the pancreatic $\beta$-cells and hepatocytes in liver (Matschinsky and Porte, 2010; Grewal et al., 2014). In pancreatic $\beta$-cells, it plays chief role by regulating glucosestimulated insulin release and in liver hepatocytes cells, it regulates the sugar metabolism. GK is an emerging target for the therapeutic management of T2D patients as it plays a key function in the regulation of carbohydrate breakdown. GK activators are the new class of drug candidates which 
act on GK enzyme and show their hypoglycemic activity (Coghlan and Leighton, 2008; Pal, 2009; Perseghin, 2010; Matschinsky et al., 2011). A broad diversity of chemical entities including benzamide derivatives (Iino et al., 2010; Pike et al., 2011; Li et al., 2011; Mao et al., 2012; Zhang et al., 2012; Park et al., 2013; Park et al., 2014; Singh et al., 2016; Tsumura et al., 2017; Wang et al., 2017; Charaya et al., 2018), acetamides (Mitsuya et al., 2009; Pfefferkorn et al., 2012; Cheruvallath et al., 2013), carboxamides (Li et al., 2010; Pfefferkorn et al., 2012a; Ye et al., 2012), acrylamides (Sidduri et al., 2010), benzimidazoles (Ishikawa et al., 2009; Takahashi et al., 2009), quinazolines (Iino et al., 2009), thiazoles (Hinklin et al., 2013), pyrimidines (Filipski et al., 2013), and urea derivatives (Zhang et al., 2012a; Li et al., 2014) have been reported in last few years to act as potent GK activators. The maximum research efforts related to GK activators had mainly focused on the benzamide derivatives owing to their orientation and binding pattern in the allosteric binding site of the GK protein (Grewal et al., 2014). In view of the critical importance of the GK activators in management of $\mathrm{T} 2 \mathrm{D}$ and the potential of benzamide derivatives as GK activators, we planned to design and synthesize some novel GK activators based on benzamide nucleus. The substitutions on benzamide nucleus were carried out in such a way that strong $\mathrm{H}$-bond and hydrophobic interactions with residues in the allosteric site of GK protein can be achieved (Figure 1).

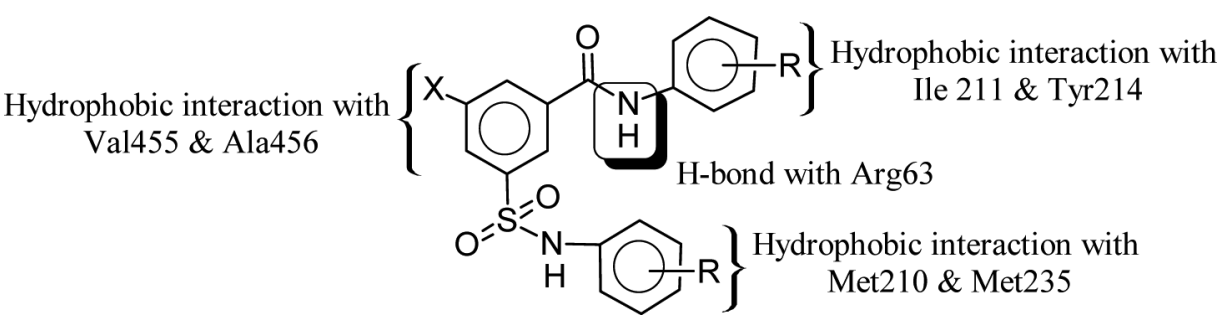

Figure 1: Pharmacophoric features and general structure of sulfamoyl benzamide derivatives designed as potential GK activators.

\section{Experimental}

\subsection{Material and Methods}

The chemicals were purchased from Spectrochem Ltd., Otto Chem. Pvt. Ltd., and SD Fine Chem. Ltd. and were utilized as such. Melting points were calculated by using open capillary tubes on a Veego VMP-D melting point apparatus and are uncorrected. The reaction completion was monitored by thin layer chromatography (TLC) on silica gel-G plates and the purity of the compounds was ascertained by single spot on TLC plate. Infrared (IR) spectra were recorded on a Shimadzu IR affinity FTIR spectrophotometer using $\mathrm{KBr}$ pellet method. ${ }^{1} \mathrm{H}$ Nuclear magnetic resonance ( $\left.{ }^{1} \mathrm{H}-\mathrm{NMR}\right)$ spectra were taken on BrukerAvance II $300 \mathrm{MHz}$ NMR spectrophotometer using DMSO- $\mathrm{d}_{6}$ as solvent and are expressed in parts per million $(\delta, \mathrm{ppm})$ downfield from tetramethylsilane (internal standard).

\subsection{Synthesis of Sulfamoyl Benzamide Derivatives}

Anhydrous 3-nitrobenzoic acid (1 mmol) was taken in a RBF fitted with a stir bar and a Claisen adapter in a cold water bath maintained between 10 and $15^{\circ} \mathrm{C}$. Chlorosulphonic acid $(8.0 \mathrm{~mL})$ was added in excess and funnel was stoppered and checked cautiously to confirm no leakage. The reaction showed exothermic reaction and when whole acid had dissolved and the exothermic reaction subsided, the reaction was completed by heating the flask on water bath at $70-80^{\circ} \mathrm{C}$ for $2 \mathrm{~h}$. The reaction mixture was cooled and transferred to $150 \mathrm{~g}$ crushed ice with stirring to break lumps. The precipitates were filtered using vacuum filtration followed by washing with cold water and product was air dried. The resulting product $(1 \mathrm{mmol})$ and commercially available amines $(1 \mathrm{mmol})$ were refluxed in acetone, until the reaction was completed as observed by TLC. The contents of the flask were cooled and precipitates of sulphonamides of 3-nitrobenzoic acid obtained were washed and dried. The different sulphonamides $(1 \mathrm{mmol})$ as obtained above and thionyl chloride $(1 \mathrm{mmol})$ were refluxed for $3 \mathrm{~h}$. On completion of reflux, the excess of thionyl chloride was distilled off to obtain the corresponding acid chlorides. The respective benzoyl chlorides $(1 \mathrm{mmol})$ were refluxed with commercially available amines $(1.5 \mathrm{mmol})$ in acetone and the final products received after evaporation of acetone were recrystallized from ethanol (Singh et al., 2016; Grewal et al., 2017; Charaya et al., 2018).

3-[(4-Bromophenyl)sulfamoyl]-N-(4-methylphenyl)-5nitrobenzamide (1): FTIR (KBr Pellets) $v \mathrm{~cm}^{-1}: 3377.55$ (NH str.), 2975.39 (CH str., Aromatic), 1616.64 (C=O str., $\mathrm{CONH}$ ), 1529.62 ( $\mathrm{NO}_{2}$ str., Asymm.), 1280.03 ( $\mathrm{CH}$ bend, Aromatic), 1394.10 ( $\mathrm{SO}_{2}$ str., $\left.\mathrm{SO}_{2} \mathrm{NH}\right), 601$ (C-Br str.).

$\mathrm{N}$-(4-bromophenyl)-3-nitro-5-[(4-nitrophenyl)sulfamoyl] benzamide (2): FTIR (KBr Pellets) $v \mathrm{~cm}^{-1}: 3354.55(\mathrm{NH}$ str.,), 2975.39 (CH str., Aromatic), 1616.64 (C=O str., amide), 1529.62 ( $\mathrm{NO}_{2}$ str., Asymm.), 128.003 ( $\mathrm{CH}$ bend., 
Aromatic), $1394.10\left(\mathrm{SO}_{2}, \mathrm{SO}_{2} \mathrm{NH}\right), 1309$ (C-N str.), 603 (C-Br str); ${ }^{1} \mathrm{H}$ NMR ( $\delta$ ppm, DMSO): $10.02(\mathrm{~s}, 1 \mathrm{H}, \mathrm{NH}$, NHCO), 8.32-8.45 (s, 3H, CH, $\mathrm{C}_{6} \mathrm{H}_{3} \mathrm{CO}$ ), 7.44-7.59 (m, $\left.4 \mathrm{H}, \mathrm{CH}, \mathrm{C}_{6} \mathrm{H}_{4}-\mathrm{NO}_{2}\right), 7.02-7.34\left(\mathrm{~m}, 4 \mathrm{H}, \mathrm{CH}, \mathrm{C}_{6} \mathrm{H}_{4}-\mathrm{Br}\right)$, $2.50\left(\mathrm{~s}, 1 \mathrm{H}, \mathrm{NH}, \mathrm{SO}_{2} \mathrm{NH}\right)$.

3-[(4-Chloro-2-nitrophenyl)sulfamoyl]-N-(4chlorophenyl)-5-nitrobenzamide (3): FTIR (KBr Pellets) $v \mathrm{~cm}^{-1}: 3354.55$ (NH str.), 3097.39 (CH str., Aromatic), 1689.64 ( $\mathrm{C}=\mathrm{O}$ str., $\mathrm{CONH}), 1529.62\left(\mathrm{NO}_{2}\right.$ str. $), 1247.03$ (CH bend, Aromatic), $1346.10\left(\mathrm{SO}_{2}, \mathrm{SO}_{2} \mathrm{NH}\right), 1072(\mathrm{C}-\mathrm{N}$ str.), 746 (C-Cl str.).

$N$-(4-Chlorophenyl)-3-((3-chlorophenyl)sulfamoyl)-5nitrobenzamide (4): FTIR ( $\mathrm{KBr}$ Pellets) $v \mathrm{~cm}^{-1}: 3304.55$ (NH str.), 3055.39 (CH str., Aromatic), $1651.64(\mathrm{C}=\mathrm{O}$ str., $\mathrm{CONH}), 1529.62$ ( $\mathrm{NO}_{2}$ str., Asymm.), 1238.03 (CH bend, Aromatic), 1350.10 ( $\left(\mathrm{SO}_{2}, \mathrm{SO}_{2} \mathrm{NH}\right), 1078$ (C-N str.), 783 (C-Cl str.); ${ }^{1} \mathrm{H}$ NMR ( 8 ppm, DMSO): 10.7 (s, $1 \mathrm{H}$, $\mathrm{NH}, \mathrm{NHCO}$ ), 8.21-8.38 (s, 3H, CH, $\mathrm{C}_{6} \mathrm{H}_{3} \mathrm{CO}$ ), 7.85-7.89 (m, $\left.4 \mathrm{H}, \mathrm{CH}, \mathrm{C}_{6} \mathrm{H}_{4}-\mathrm{Cl}\right), 7.55-7.59\left(\mathrm{~m}, 4 \mathrm{H}, \mathrm{CH}, \mathrm{C}_{6} \mathrm{H}_{4}-\mathrm{Cl}\right)$, $2.50\left(\mathrm{~s}, 1 \mathrm{H}, \mathrm{NH}, \mathrm{SO}_{2} \mathrm{NH}\right)$.

$\mathrm{N}$-(4-Chlorophenyl)-3-((2-chlorophenyl)sulfamoyl)-5nitrobenzamide (5): FTIR (KBr Pellets) $v \mathrm{~cm}^{-1}: 3277.55$ (NH str.), 3194.39 (CH str., Aromatic), 1689.64 (C=O str., $\mathrm{CONH}), 1529.62\left(\mathrm{NO}_{2}\right.$ str.), 1259.03 (CH bend, Aromatic), $1319.10\left(\mathrm{SO}_{2}, \mathrm{SO}_{2} \mathrm{NH}\right), 1053$ (C-N str.), 845 (C-Cl str.).

$N$-(4-Bromophenyl)-3-((2-chlorophenyl)sulfamoyl)-5nitrobenzamide (6): FTIR (KBr Pellets) $v \mathrm{~cm}^{-1}$ : FTIR (KBr Pellets) $v \mathrm{~cm}^{-1}: 3305.55$ (NH str.), 3094.39 (CH str., Aromatic), $1589.64(\mathrm{C}=\mathrm{O}$ str., $\mathrm{CONH}), 1529.62$ ( $\mathrm{NO}_{2}$ str.), 1205.03 (CH bend, Aromatic), $1348.10\left(\mathrm{SO}_{2}\right.$, $\mathrm{SO}_{2} \mathrm{NH}$ ), 1012 (C-N str.), 815 (C-Cl str.), 682 (C-Br str.); ${ }^{1} \mathrm{H}$ NMR ( $\delta$ ppm, DMSO): 10.02 (s, 1H, NH, NHCO), 8.34-8.36 (s, 3H, CH, $\left.\mathrm{C}_{6} \mathrm{H}_{3} \mathrm{CO}\right), 7.44-7.59$ (m, 4H, CH, $\left.\mathrm{C}_{6} \mathrm{H}_{4}-\mathrm{Cl}\right), 7.57-7.61\left(\mathrm{~m}, 4 \mathrm{H}, \mathrm{CH}, \mathrm{C}_{6} \mathrm{H}_{4}-\mathrm{Br}\right), 2.50(\mathrm{~s}, 1 \mathrm{H}$, $\left.\mathrm{NH}, \mathrm{SO}_{2} \mathrm{NH}\right)$.

$\mathrm{N}$-(4-Bromophenyl)-3-((4-chloro-2-nitrophenyl) sulfamoyl)-5-nitrobenzamide (7): FTIR ( $\mathrm{KBr}$ Pellets) $v \mathrm{~cm}^{-1}: 3334.55$ (NH str.), 2992.39 (CH str., Aromatic), 1546.64 (C=O str., $\mathrm{CONH}), 1251.62\left(\mathrm{NO}_{2}\right.$ str.), 1251.03 (CH bend, Aromatic), $1346.10\left(\mathrm{SO}_{2}, \mathrm{SO}_{2} \mathrm{NH}\right), 1012(\mathrm{C}-\mathrm{N}$ str.), 822 (C-Cl str.), 669 (C-Br str.); ${ }^{2} \mathrm{H}$ NMR ( $\delta$ ppm, DMSO): 10.7 (s, 1H, NH, CONH), 8.16-8.28 (s, 3H, CH, $\left.\mathrm{C}_{6} \mathrm{H}_{3} \mathrm{CO}\right)$, 7.41-7.46 (m, 3H, CH, $\left.\mathrm{C}_{6} \mathrm{H}_{3}-\mathrm{Cl}_{-} \mathrm{NO}_{2}\right)$, 7.527.69 (m, 4H, CH, $\left.\mathrm{C}_{6} \mathrm{H}_{4}-\mathrm{Br}\right), 2.51$ (s, 1H, NH, SO $\mathrm{SH}_{2}$ ).

3-[(3-Bromophenyl)sulfamoyl]-5-nitro- $N$-(4-nitrophenyl) benzamide (8): FTIR (KBr Pellets) $v \mathrm{~cm}^{-1}: 3400.55$ (NH str.), 3080.39 (CH str., Aromatic), 1610.64 ( $\mathrm{C}=\mathrm{O}$ str., CONH), 1350.62 ( $\mathrm{NO}_{2}$ str.), 1205.03 (CH bend, Aromatic), $1350.10\left(\mathrm{SO}_{2}, \mathrm{SO}_{2} \mathrm{NH}\right), 1010$ (C-N str.), 682 (C-Br str.); ${ }^{1} \mathrm{H}$ NMR ( $\left.\delta \mathrm{ppm}, \mathrm{DMSO}\right): 10.76$ (s, 1H, NH, NHCO),
8.32-8.63 (s, 3H, CH, $\mathrm{C}_{6} \mathrm{H}_{3} \mathrm{CO}$ ), 7.82-8.01 (m, 4H, CH, $\mathrm{C}_{6} \mathrm{H}_{4}-\mathrm{NO}_{2}$ ), 7.26-7.34 (m, 4H, CH, $\left.\mathrm{C}_{6} \mathrm{H}_{4}-\mathrm{Br}\right), 2.51(\mathrm{~s}, 1 \mathrm{H}$, $\left.\mathrm{NH}, \mathrm{SO}_{2} \mathrm{NH}\right)$.

N-(4-Bromophenyl)-3-(methylsulfamoyl)-5nitrobenzamide (9): FTIR (KBr Pellets) $v \mathrm{~cm}^{-1}$ : FTIR (KBr Pellets) $v \mathrm{~cm}^{-1}: 3394.55$ (NH str.), $2989.39(\mathrm{CH}$ str., Aromatic), 1616.64 (C=O str., $\mathrm{CONH}), 2858$ (C-C str.) $1398.62\left(\mathrm{NO}_{2}\right.$ str.), 1203.03 ( $\mathrm{CH}$ bend, Aromatic), $1350.10\left(\mathrm{SO}_{2}, \mathrm{SO}_{2} \mathrm{NH}\right), 1014$ (C-N str.), 603 (C-Br str.).

3-((4-Bromophenyl)sulfamoyl)-5-nitro-N-(4-nitrophenyl) benzamide (10): FTIR (KBr Pellets) $v \mathrm{~cm}^{-1}: 3215.55(\mathrm{NH}$ str.), 2973.39 (CH str., Aromatic), 1610.64 ( $\mathrm{C}=\mathrm{O}$ str., CONH), 1350.62 ( $\mathrm{NO}_{2}$ str.), 1205.03 (CH bend, Aromatic), $1531.10\left(\mathrm{SO}_{2}, \mathrm{SO}_{2} \mathrm{NH}\right), 1013$ (C-N str.), 667 (C-Br str.).

3-((4-Bromophenyl)sulfamoyl)-N-(4-chlorophenyl)-5nitrobenzamide (11): FTIR (KBr Pellets) $v \mathrm{~cm}^{-1}: 3331.55$ (NH str.), 3078.39 (CH str., Aromatic), 1624.64 (C=O str., $\mathrm{CONH}), 1327.62\left(\mathrm{NO}_{2}\right.$ str.), 1207.03 (CH bend, Aromatic), $1327.10\left(\mathrm{SO}_{2}, \mathrm{SO}_{2} \mathrm{NH}\right), 1089$ (C-N str.), 667 (C-Br str.) 732 (C-Cl str.).

\subsection{Docking Studies}

In silico docking studies were performed out for the synthesized derivatives in the binding site of GK using AutoDock Vina (Trott \& Olson, 2010), graphical user interface, AutoDock Tools (Morris et al., 2009) and PyMOL (The PyMOL Molecular Graphics System, Schrödinger, LLC) installed on Windows (Trott \& Olson, 2010; Morris et al., 2009). Two-dimensional structures of the ligands were drawn using Marvin Sketch (Marvin 15.9.21, 2015, ChemAxon) and converted to 3-D using Frog2 server (Miteva et al., 2010). The co-crystallized GK information was obtained from the RCSB protein data bank (Berman et al., 2000) and after evaluating a number of entries, the best ligand bound complex (PDB entry: 3IMX) was selected by analyzing 3-D structures with highest resolution. The same protocol for molecular docking of the synthesized sulfamoyl benzamide derivatives using AutoDock Vina was used as reported in detail in earlier publications (Singh et al., 2016; Grewal et al., 2017; Grewal et al., 2017a). At the end of docking, the ligand poses with the most favorable binding free energy $(\Delta \mathrm{G}, \mathrm{kcal} / \mathrm{mol})$ were selected. The H-bond interactions, hydrophobic interactions etc., were analysed further for the docked poses of all the ligands using PyMOL and the best poses in the binding site were selected for further analysis.

\subsection{Evaluation of Antidiabetic Activity}

Male Sprague-Dawley rats weighing 160-180 g were procured from Lala Lajpat Rai University of Veterinary 
and Animal Sciences, Hisar. The rats were kept and maintained at controlled room temperature $\left(22 \pm 2^{\circ} \mathrm{C}\right)$ and humidity $(55 \pm 5 \%)$ with $12: 12 \mathrm{~h}$ light and dark cycle. All the rats were fed with the normal pellet diet and water ad libitum, prior to the dietary manipulation. Permission was taken from institutional animal ethics committee and associated guidelines of Committee for the Purpose of Control and Supervision of Experiments on Animals, Govt. of India were followed for conducting this study (Approval No. JCDMCOP/IAEC/06/14/23). A cohort of male Wistar rats was fasted for at least 8 hours. Hyperglycemia was induced in each fasted rat by administering alloxan monohydrate $(150 \mathrm{mg} / \mathrm{kg}$ body weight; intraperitoneal) in normal saline. Blood glucose was checked using a glucometer after $72 \mathrm{~h}$ post-induction of hyperglycemia and only the rats with established hyperglycemia were included for subsequent experiment. Based on the screening carried out in the molecular docking studies, the selected sulfamoyl benzamide derivatives $(2,6,7,8$ and 10) at a dose of $50 \mathrm{mg} / \mathrm{kg}$ and metformin (standard antidiabetic drug) at a dose of $100 \mathrm{mg} / \mathrm{kg}$ were administered orally in
$0.5 \%$ CMC solution to a cohort of diabetic rats $(n=6)$. Untreated diabetic group received only the vehicle $(0.5 \%$ $\mathrm{CMC}$ solution). Blood glucose levels were measured at specified time intervals $(0,2,4$ and $6 \mathrm{~h})$ in all the rats (Akinola et al., 2012).

\section{Results and Discussion}

\subsection{Chemistry}

The general scheme followed for synthesizing designed sulfamoyl benzamide derivatives is presented in Figure 2. 3-(Chlorosulphonyl)-5-nitrobenzoic acid was prepared by chlorosulphonation of 3-nitrobenzoic acid followed by refluxing with amines to obtain the sulphonamides. The different sulphonamides were refluxed with thionyl chloride to get their respective benzoyl chlorides which were then refluxed with available aromatic amines to get the designed derivatives. The physiochemical properties of the final synthesized compounds are presented in Table 1 and all the synthesized compounds were characterized using FTIR and ${ }^{1} \mathrm{H}-\mathrm{NMR}$ spectroscopy.<smiles>O=C(O)c1cccc([N+](=O)[O-])c1</smiles>

(b)<smiles>[R]NS(=O)(=O)c1cc(C(=O)O)cc([N+](=O)[O-])c1</smiles>

(c)<smiles>[R]NS(=O)(=O)c1cc(C(=O)Cl)cc([N+](=O)[O-])c1</smiles>

(d)<smiles>[R]NC(=O)c1cc([N+](=O)[O-])cc([R](=O)(=O)N[R])c1</smiles>

(1-11)

Figure 2: Synthetic route followed for sulfamoyl benzamide derivatives. Reagents and conditions: (a) Chlorosulphonic acid, 80 -, $2 \mathrm{~h}$; (b) $\mathrm{NH}_{2}-\mathrm{R}^{1}$, acetone, reflux; (c) Thionyl chloride, acetone, reflux; (d) $\mathrm{NH}_{2}-\mathrm{R}^{2}$, acetone, reflux.

Table 1: Physicochemical properties of the synthesized sulfamoyl benzamide derivatives.

\begin{tabular}{|c|c|c|c|c|c|c|}
\hline Compound & $\mathbf{R}^{1}$ & $\mathbf{R}^{2}$ & Mol. formula & M. Pt. $\left({ }^{\circ} \mathrm{C}\right)$ & $\mathbf{R}_{\mathrm{f}}^{*}$ & $\%$ Yield \\
\hline 1 & & & $\mathrm{C}_{19} \mathrm{H}_{13} \mathrm{Br}_{2} \mathrm{~N}_{3} \mathrm{O}_{5} \mathrm{~S}$ & $150-155$ & 0.72 & 45 \\
\hline 2 & & & $\mathrm{C}_{19} \mathrm{H}_{13} \mathrm{BrN}_{4} \mathrm{O}_{7} \mathrm{~S}$ & $172-177$ & 0.65 & 48 \\
\hline
\end{tabular}


3<smiles>Cc1ccc(Cl)cc1[N+](=O)[O-]</smiles>

4<smiles>Cc1cccc(Cl)c1</smiles>

5<smiles>Cc1ccc(Cl)cc1</smiles>

6<smiles>Cc1ccccc1Cl</smiles>

7<smiles>Cc1ccc(Cl)cc1[N+](=O)[O-]</smiles>

8<smiles>Cc1cccc(Br)c1</smiles>

9<smiles>CC</smiles>

10<smiles>Cc1ccc(Br)cc1</smiles>

11<smiles>Cc1ccc(Cl)cc1</smiles>

$\mathrm{C}_{19} \mathrm{H}_{12} \mathrm{Cl}_{2} \mathrm{~N}_{4} \mathrm{O}_{7} \mathrm{~S} \quad 160-165$

$\mathrm{C}_{19} \mathrm{H}_{13} \mathrm{Cl}_{2} \mathrm{~N}_{3} \mathrm{O}_{5} \mathrm{~S} \quad 165-179$

$\mathrm{C}_{19} \mathrm{H}_{13} \mathrm{Cl}_{2} \mathrm{~N}_{3} \mathrm{O}_{5} \mathrm{~S} \quad 165-170 \quad 0.60$

$\mathrm{C}_{19} \mathrm{H}_{13} \mathrm{BrClN}_{3} \mathrm{O}_{5} \mathrm{~S}$

$175-180$

0.54

49<smiles>Cc1ccc(Br)cc1</smiles>

$\mathrm{C}_{19} \mathrm{H}_{12} \mathrm{BrClN}_{4} \mathrm{O}_{7} \mathrm{~S}$

177-183

0.71

38<smiles>Cc1ccc([N+](=O)[O-])cc1</smiles>

$\mathrm{C}_{19} \mathrm{H}_{13} \mathrm{BrN}_{4} \mathrm{O}_{7} \mathrm{~S}$

172-177

0.70

$\mathrm{C}_{14} \mathrm{H}_{10} \mathrm{BrN}_{3} \mathrm{O}_{5} \mathrm{~S}$

155-160

0.59<smiles>Cc1ccc([N+](=O)[O-])cc1</smiles>

$\mathrm{C}_{19} \mathrm{H}_{13} \mathrm{BrN}_{4} \mathrm{O}_{7} \mathrm{~S}$

$165-170$

0.78

54

$\mathrm{C}_{19} \mathrm{H}_{13} \mathrm{BrClN}_{3} \mathrm{O}_{5} \mathrm{~S}$

180-185

54

55

9

8

0<smiles>Cc1ccc(Cl)cc1</smiles>

*TLC mobile phase: Benzene: Ethyl acetate (7:3).

The ${ }^{1} \mathrm{H}-\mathrm{NMR}$ spectra of synthesized sulfamoyl benzamide derivatives showed singlet signal equivalent to one proton of the $-\mathrm{NHCO}$ group around $\delta 10 \mathrm{ppm}$, confirming the formation of amide bond in the synthesized benzamide derivatives by the reaction of various benzoyl chlorides with commercially available anilines. The presence of singlet signal in the ${ }^{1} \mathrm{H}-\mathrm{NMR}$ spectra of the synthesized compounds for the $\mathrm{NH}$ proton of $\mathrm{SO}_{2} \mathrm{NH}$ group was observed around $\delta 2.5$ ppm which confirmed the formation of sulphonamides by the reaction of various sulfonyl chlorides with commercially available aliphatic and aromatic amines. The FTIR spectra of synthesized derivatives showed the presence of $\mathrm{NH}$ stretching of NHCO around 3200-3300 $\mathrm{cm}^{-1}$, aromatic - $\mathrm{CH}$ stretching above $3000 \mathrm{~cm}^{-1}$ as well as $-\mathrm{SO}_{2}$ asymmetric and symmetric stretching around $1350 \mathrm{~cm}^{-1}$ and 1150 $\mathrm{cm}^{-1}$ respectively, thus supporting the fact that an amide linkage and a sulphonamide functional group was present in the structure of synthesized benzamide derivatives. The various stretching and bending vibration related to various functional groups were present in the FTIR spectra of the synthesized compounds.

\subsection{Docking Studies}

Lead optimization of the synthesized compounds was done by computation of drug-likeness properties (molecular weight, log P, hydrogen bond donors (HBD), and hydrogen bond acceptors (HBA). Most of the compounds selected for in silico docking studies were found to possess drug like properties as contrived by Lipinski's rule of five (Table 2). The docking simulations were carried out by AutoDock Vina, by energy minimization and optimization of designed ligands in the allosteric binding site of GK protein and validated by docking of 3IMX ligand in the allosteric binding site of GK protein. Docking score of synthesized 
derivatives are presented in Table 2. Out of these derivatives, compounds 2, 6, 7, 8 and 10 observed appreciable binding in the allosteric site as determined by analyzing the $\mathrm{H}$-bond and hydrophobic interactions of the selected best docked poses. The docking studies of these molecules suggested a complimentary fit in the allosteric site of GK protein. On the basis of their lowest binding free energy $(\mathrm{kcal} / \mathrm{mol})$ and docking interactions in the binding site, compounds $1,2,5$, and 8 were further analyzed in details by PyMOL.

Table 2: Molecular properties and docking score of the synthesized sulfamoyl benzamide derivatives.

\begin{tabular}{cccccc}
\hline Compound & Mol. Wt. & $\mathbf{l o g}^{*}$ & HBA $^{*}$ & HBD $^{*}$ & $\begin{array}{c}\text { Docking score } \\
(\boldsymbol{\Delta} \mathbf{G})\end{array}$ \\
\hline $\mathbf{1}$ & 555.20 & 5.03 & 5 & 2 & -8.7 \\
$\mathbf{2}$ & 521.30 & 4.20 & 7 & 2 & -9.3 \\
$\mathbf{3}$ & 511.29 & 4.64 & 7 & 2 & -8.9 \\
$\mathbf{4}$ & 466.29 & 4.70 & 5 & 2 & -8.8 \\
$\mathbf{5}$ & 466.29 & 4.70 & 5 & 2 & -8.7 \\
$\mathbf{6}$ & 510.74 & 4.87 & 5 & 2 & -9.3 \\
$\mathbf{7}$ & 455.74 & 4.81 & 7 & 2 & -9.9 \\
$\mathbf{8}$ & 521.30 & 4.20 & 7 & 2 & -9.0 \\
$\mathbf{9}$ & 414.23 & 2.60 & 5 & 2 & -8.0 \\
$\mathbf{1 0}$ & 521.30 & 4.20 & 7 & 2 & -9.0 \\
$\mathbf{1 1}$ & 510.74 & 4.87 & 5 & 2 & -8.9 \\
\hline
\end{tabular}

*Mol. Wt., Log P, HBA, and HBD were calculated using MarvinSketch (2015).
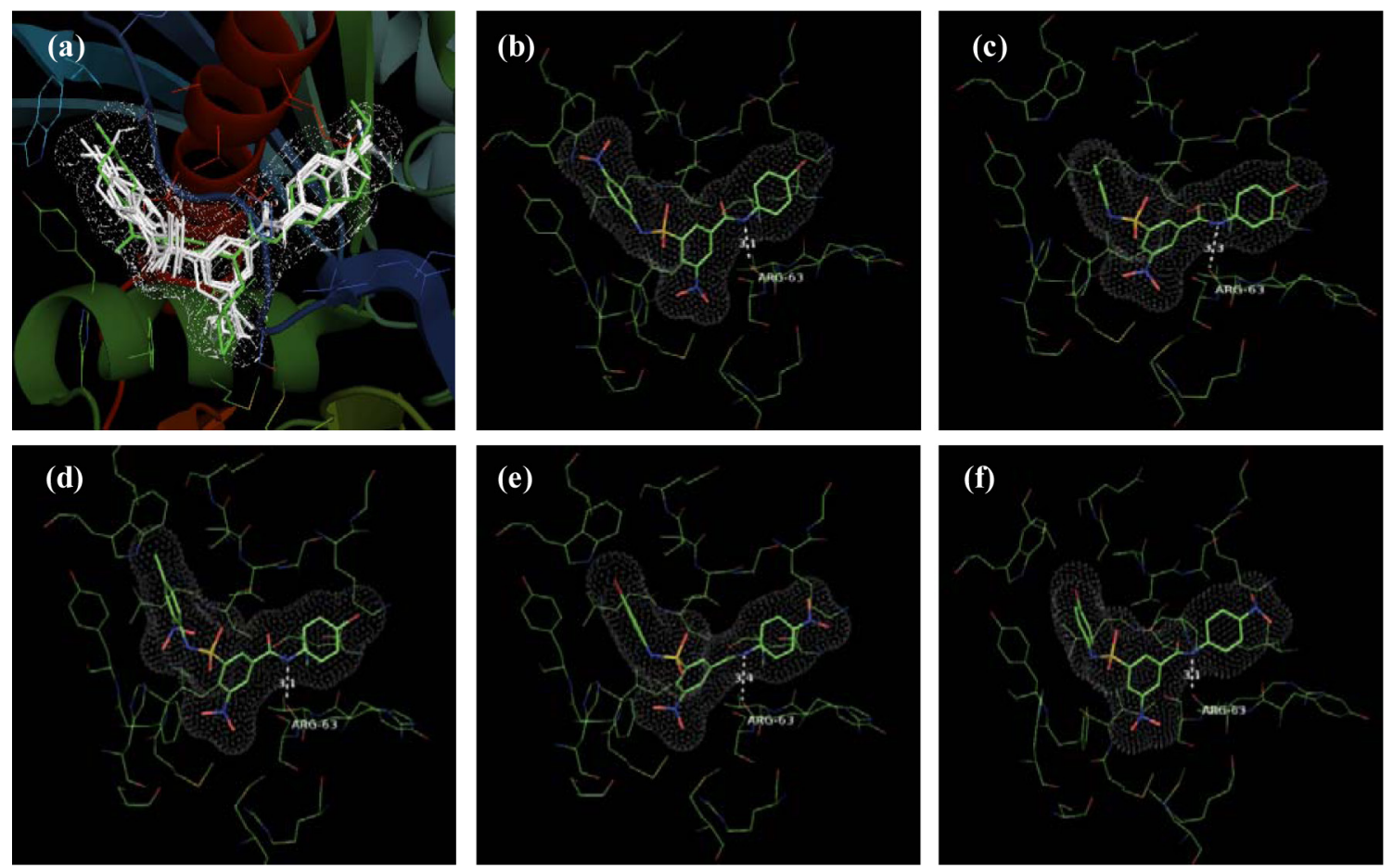

Figure 3: (a) Overlay of the docked pose of compounds 2, 6, 7, 8 and 10 (white) with that of PDB Ligand 3IMX (green); (b) Docked pose showing H-bond interactions for compound 2; (c) Docked pose showing H-bond interactions for compound 6; (d) Docked pose showing H-bond interactions for compound 7; (e) Docked pose showing H-bond interactions for compound 8; (f) Docked pose showing H-bond interactions for compound 10 in the allosteric site of GK protein. 
Docked pose showing overlay of the selected compounds with that of the PDB ligand 3IMX are presented in Figure 3. An overlay of docked poses of the selected compounds 2 , $6,7,8$ and 10 with that of 3IMX ligand showed that the selected compounds had the similar binding pattern in the allosteric site of the GK enzyme as that of co-crystallized ligand (Figure 3a). The 4-bromophenyl group of compound 2 showed hydrophobic interactions with Val455 and Ala456, phenyl ring packs between Tyr214 and Met210 residues whereas the 4-bromophenyl group of sulphonamide oriented into the hydrophobic pocket comprising Trp99, Tyr215 and Leu451. Similarly overlay of the docked poses of compounds $6,7,8$ and 10 also showed that these selected compounds had the similar binding pattern in the allosteric site of the GK protein as that of co-crystallized ligand. The docked pose of compounds 2, 6, 7, 8 and 10 in the allosteric binding site of GK showed the $\mathrm{H}$-bond interaction between the amide carbonyl of benzamide and $\mathrm{NH}$ of Arg63 on GK protein with H-bond distance of 3.1, 3.3, 3.1, 3.4, and $3.1 \AA$ (Figure 3b-3f). Thus, the molecular docking study of designed sulfamoyl benzamide derivatives in the allosteric binding site GK protein helped us in predicting that the designed benzamide derivatives could act as potent GK activators.

\subsection{Antidiabetic Activity}

The selected compounds 2, 6, 7, 8 and 10 screened by in silico docking studies were further studied for their antidiabetic effect in induced diabetic rats. The results of antidiabetic activity measured as blood glucose levels $(\mathrm{mg} / \mathrm{dl})$ at different time intervals are presented in Figure 4. The results of antidiabetic activity indicated that compounds 2 and 7 had better glucose lowering effects in diabetic animals than other compounds. Compound 2 lowered blood glucose levels in diabetic rats but not equivalent to that of the standard drug metformin. Compounds 6 and 8 were found to be ineffective as antidiabetic agents. Compound 10 slightly lowered blood glucose level in diabetic rats at $2 \mathrm{~h}$ but it was ineffective at $4 \mathrm{~h}$ and $6 \mathrm{~h}$. Compound 7 was almost similarly effective in lowering blood glucose levels at $2 \mathrm{~h}$ compared to that of the standard drug metformin and showed a significant decrease in blood glucose levels at $4 \mathrm{~h}$ and $6 \mathrm{~h}$. The antidiabetic activity data was statistically analyzed by oneway ANOVA. All the data was significantly different from the control group $(\mathrm{p}<0.05)$.

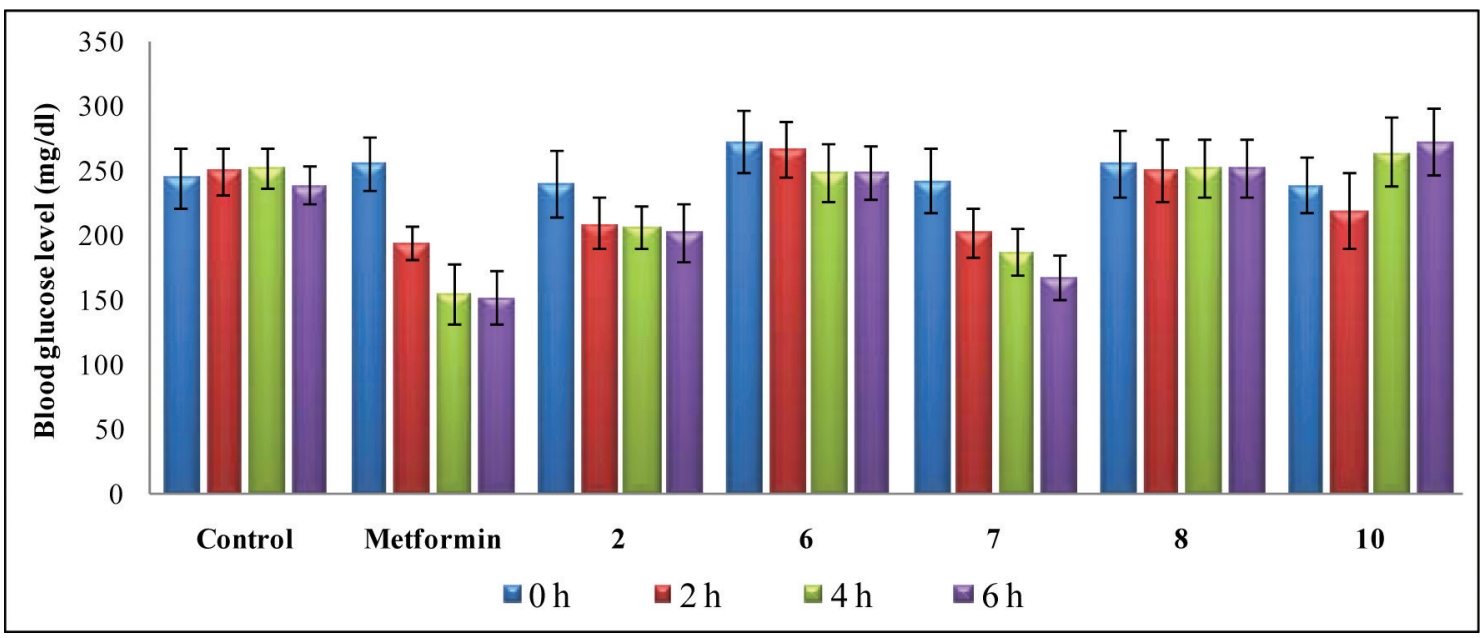

Figure 4: Blood glucose levels of selected molecules at different time intervals. All the values are mean of six measurements \pm SD. ${ }^{*} D a t a$ was significantly different compared to the control group ( $\mathrm{p}<0.05)$.

\section{Conclusion}

A new series of sulfamoyl benzamide derivatives were designed based on the pharmacophoric features required for binding of GK activators with GK by means of substitution at amide linker and addition of sulphonamide moieties at the aromatic ring. Amongst the several synthesized derivatives, compounds $2,6,7,8$ and 10 showed good interactions with the residues in the allosteric binding site GK protein in molecular docking studies. Amongst, the selected compounds tested in vivo, compound 7 displayed greater antihyperglycemic efficacy in antidiabetic studies. The results of the in vivo antidiabetic assay were in accordance to that of in silico molecular docking studies. The molecular properties of these newer benzamide derivatives were also found to follow the Lipinski's rule of five for drug-like property. These synthesized molecules can behave as the early hit molecules for further development of safe, potent and oral GK activators for the potential treatment of diabetic disorders. 


\section{Acknowledgements}

The authors are thankful to the Management, Jan Nayak Ch. Devi Lal Vidyapeeth, Sirsa (Haryana) for their support and encouragement for this research work.

\section{References}

1. Akinola, O., Gabriel, M., Suleiman, A., and Olorunsogbon, F. (2012). Treatment of alloxaninduced diabetic rats with metformin or glitazones is associated with amelioration of hyperglycaemia and neuroprotection. The Open Diabetes Journal, 5, 8-12. https://doi.org/10.2174/1876524601205010008

2. Bastaki, S. (2005). Diabetes mellitus and its treatment. International Journal of Diabetes Metabolism, 13, 111-134.

3. Brownlee, M. (2001). Biochemistry and molecular cell biology of diabetic complications. Nature, 414, 813-820.

https://doi.org/10.1038/414813

4. Cade, W. T. (2008). Diabetes-related microvascular and macrovascular diseases in the physical therapy setting. Physical Therapy, 88, 1322-1335.

https://doi.org/10.2522/ptj.20080008

5. Charaya N., Pandita D., Grewal A. S., and Lather V. (2018). Design, synthesis and biological evaluation of novel thiazol-2-yl benzamide derivatives as glucokinase activators. Computational Biology and Chemistry, 73, 221-229.

https://doi.org/10.1016/j.compbiolchem.2018.02.018

6. Cheruvallath, Z. S., Gwaltney, S. L., Sabat, M., Tang, M., Feng, J., Wang, H., et al. (2013). Design, synthesis and SAR of novel glucokinase activators. Bioorganic and Medicinal Chemistry Letters, 23(7), 2166-2171. https://doi.org/10.1016/j.bmcl.2013.01.093

7. Coghlan, M. and Leighton, B. (2008). Glucokinase activators in diabetes management. Expert Opinion on Investigational Drugs, 17(2), 145-167.

https://doi.org/10.1517/13543784.17.2.145

8. Filipski, K. J., Guzman-Perez, A., Bian, J., Perreault, C., Aspnes, G. E., Didiuk, M. T., et al. (2013). Pyrimidone-based series of glucokinase activators with alternative donor-acceptor motif. Bioorganic and Medicinal Chemistry Letters, 23(16), 4571-4578. https://doi.org/10.1016/j.bmcl.2013.06.036

9. Grewal, A. S., Sekhon, B. S., and Lather, V. (2014). Recent updates on glucokinase activators for the treatment of type 2 diabetes mellitus. Mini Reviews in Medicinal Chemistry, 14(7), 585-602. https://doi.org/10.2174/1389557514666140722082 713
10. Grewal, A. S., Bhardwaj, S., Pandita, D., Lather, V. and Sekhon, B. S. (2016). Updates on aldose reductase inhibitors for management of diabetic complications and non-diabetic diseases. Mini Reviews in Medicinal Chemistry, 16(2), 120-162.

https://doi.org/10.2174/1389557515666150909143 737

11. Grewal, A. S., Lather, V., Pandita, D. and Bhayana, G. (2017). Synthesis, docking and biological evaluation of phenylacetic acid and trifluoromethylphenyl substituted benzamide derivatives as potential PPAR $\delta$ agonists. Letters in Drug Design and Discovery, 14(11), 1239-1251.

https://doi.org/10.2174/1570180814666170327164 443

12. Grewal, A. S., Viney Lather, V., Pandita, D. and Dalal, R. (2017). Synthesis, docking and anti-inflammatory activity of triazole amine derivatives as potential phosphodiesterase- 4 inhibitors. Anti-Inflammatory and Anti-Allergy Agents in Medicinal Chemistry, 16(1), 58-67.

https://doi.org/10.2174/1871523016666170616115 752

13. Hinklin, R. J., Boyd, S. A., Chicarelli, M. J., Condroski, K. R., DeWolf, W. E., Lee, P. A., et al. (2013). Identification of a new class of glucokinase activators through structure-based design. Journal of Medicinal Chemistry, 56(19), 7669-7678.

https://doi.org/10.1021/jm401116k

14. Iino, T., Sasaki, Y., Bamba, M., Mitsuya, M., Ohno, A., Kamata, K., et al. (2009). Discovery and structureactivity relationships of a novel class of quinazoline glucokinase activators. Bioorganic and Medicinal Chemistry Letters, 19(19), 5531-5538. https://doi.org/10.1016/j.bmcl.2009.08.064

15. Iino, T., Hashimoto, N., Hasegawa, T., Chiba, M., Eiki, J. and Nishimura, T. (2010). Metabolic activation of N-thiazol-2-yl benzamide as glucokinase activators: impacts of glutathione trapping on covalent binding. Bioorganic and Medicinal Chemistry Letters, 20(5), 1619-1622.

https://doi.org/10.1016/j.bmcl.2010.01.041

16. Ishikawa, M., Nonoshita, K., Ogino, Y., Nagae, Y., Tsukahara, D., Hosaka, H., et al. (2009). Discovery of novel 2-(pyridine-2-yl)-1H-benzimidazole derivatives as potent glucokinase activators. Bioorganic and Medicinal Chemistry Letters, 19(15), 4450-4454. https://doi.org/10.1016/j.bmcl.2009.05.038

17. Kohei, K. (2010). Pathophysiology of type 2 diabetes and its treatment policy. Japan Medical Association Journal, 53, 41-46. 
18. Li, F., Zhu. Q., Zhang, Y., Feng, Y., Leng, Y. and Zhang, A. (2010). Design, synthesis, and pharmacological evaluation of $\mathrm{N}$-(4-mono and 4,5-disubstituted thiazole-2-yl)-2-aryl-3-(tetrahydro-2H-pyran-4-yl) propanamides as glucokinase activators. Bioorganic and Medicinal Chemistry, 18(11), 3875-3884.

https://doi.org/10.1016/j.bmc.2010.04.038

19. Li, Y. Q., Zhang, Y. L., Hu, S. Q., Wang, Y. L., Song, H. R., Feng, Z.Q. et al. (2011). Design, synthesis and biological evaluation of novel glucokinase activators. Chinese Chemical Letters, 22(1), 73-76. https://doi.org/10.1016/j.cclet.2010.07.023

20. Li, Y., Tian, K., Qin, A., Zhang, L., Huo, L., Lei, L. et al. (2014) Discovery of novel urea derivatives as dual-target hypoglycemic agents that activate glucokinase and PPAR $\gamma$. European Journal of Medicinal Chemistry, 76, 182-192.

https://doi.org/10.1016/j.ejmech.2014.02.024

21. Mao, W., Ning, M., Liu, Z., Zhu, Q., Leng, Y. and Zhang, A. (2012). Design, synthesis, and pharmacological evaluation of benzamide derivatives as glucokinase activators. Bioorg. Medicinal Chemistry, 20(9), 2982-2991. https://doi.org/10.1016/j.bmc.2012.03.008

22. Matschinsky, F. M. and Porte, D. (2010) Glucokinase activators (GKAs) promise a new pharmacotherapy for diabetics. F1000 Medicine Reports, 2, 43.

https://doi.org/10.3410/M2-43

23. Matschinsky, F. M., Zelent, B., Doliba, N., Li, C., Vanderkooi, J. M., Naji, A. et al. (2011). Glucokinase activators for diabetes therapy. Diabetes Care, 34, S236-S243. https://doi.org/10.2337/dc11-s236

24. Miteva, M. A., Guyon, F. and Tufféry, P. (2010). Frog2: Efficient 3 D conformation ensemble generator for small compounds. Nucleic Acids Research, 38, W622-627. https://doi.org/10.1093/nar/gkq325

25. Mitsuya, M., Kamata, K., Bamba, M., Watanabe, H., Sasaki, Y., Sasaki, K. et al. (2009). Discovery of novel 3,6-disubstituted 2-pyridinecarboxamide derivatives as GK activators. Bioorganic and Medicinal Chemistry Letters, 19(10), 2718-2721.

https://doi.org/10.1016/j.bmcl.2009.03.137

26. Morris, G. M., Huey, R., Lindstrom, W., Sanner, M. F., Belew, R. K., Goodsell, D. S. et al. (2009). Autodock4 and AutoDockTools4: automated docking with selective receptor flexiblity. Journal of Computational Chemistry, 16, 2785-2791. https://doi.org/10.1002/jcc.21256

27. Olokoba, A. B., Obateru, O. A. and Olokoba, L. B. (2012). Type 2 diabetes mellitus: a review of current trends. Oman Medical Journal, 27, 269-273. https://doi.org/10.5001/omj.2012.68
28. Pal, M. (2009). Recent advances in glucokinase activators for the treatment of type 2 diabetes. Drug Discovery Today, 14, 784-792.

https://doi.org/10.1016/j.drudis.2009.05.013

29. Pal, M. (2009a). Medicinal chemistry approaches for glucokinase activation to treat type 2 diabetes. Current Medicinal Chemistry, 16(29), 3858-3874.

https://doi.org/10.2174/092986709789177993

30. Park, K., Lee, B. M., Kim, Y. H., Han, T., Yi, W., Lee, D.H. et al. (2013). Discovery of a novel phenylethyl benzamide glucokinase activator for the treatment of type 2 diabetes mellitus. Bioorganic and Medicinal Chemistry Letters, 23(2), 537-542.

https://doi.org/10.1016/j.bmcl.2012.11.018

31. Park, K., Lee, M., Hyun, H., Lee, H., Choi, H., Kim, H. et al. (2014). Discovery of 3-(4-methanesulfonylphenoxy)-N-[1-(2-methoxy-ethoxymethyl)-1Hpyrazol-3-yl]-5-(3-methylpyridin-2-yl)-benzamide as a novel glucokinase activator (GKA) for the treatment of type 2 diabetes mellitus. Bioorganic and Medicinal Chemistry, 22(7), 2280-2293.

https://doi.org/10.1016/j.bmc.2014.02.009

32. Perseghin, G. (2010). Exploring the in vivo mechanisms of action of glucokinase activators in type 2 diabetes. The Journal of Clinical Endocrinology and Metabolism, 95(11), 4871-4873.

https://doi.org/10.1210/jc.2010-2049

33. Pfefferkorn, J. A., Guzman-Perez, A., Litchfield, J., Aiello, R., Treadway, J. L., Pettersen, J., et al. (2012). Discovery of (S)-6-(3-cyclopentyl-2-(4(trifluoromethyl)-1H-imidazol- 1-yl)propanamido) nicotinic acid as a hepatoselective glucokinase activator clinical candidate for treating type 2 diabetes mellitus. Journal of Medicinal Chemistry, 55(3), 1318-1333. https://doi.org/10.1021/jm2014887

34. Pfefferkorn, J. A., Tu, M., Filipski, K. J., GuzmanPerez, A., Bian, J., Aspnes, G. E. et al. (2012a). The design and synthesis of indazole and pyrazolopyridine based glucokinase activators for the treatment of type 2 diabetes mellitus. Bioorganic and Medicinal Chemistry Letters, 22(23), 7100-7105. https://doi.org/10.1016/j.bmcl.2012.09.082

35. Pike, K. G., Allen, J. V., Caulkett, P. W., Clarke, D. S., Donald, C. S., Fenwick, M. L. et al. (2011). Design of a potent, soluble glucokinase activator with increased pharmacokinetic half-life. Bioorganic and Medicinal Chemistry Letters, 21(11), 3467-3470. https://doi.org/10.1016/j.bmcl.2011.03.093

36. Sidduri, A., Grimsby, J. S., Corbett, W. L., Sarabu, R., Grippo, J. F., Lou, J. et al. (2010). 2,3-Disubstituted acrylamides as potent glucokinase activators. 
Bioorganic and Medicinal Chemistry Letters, 20(19), 5673-5676.

https://doi.org/10.1016/j.bmcl.2010.08.029

37. Singh, R., Lather, V., Pandita, D., Vikramjeet, J., Karthikeyan, A. N. and Singh, A. S. (2016). Synthesis, docking and antidiabetic activity of some newer benzamide derivatives as potential glucokinase activators. Letters in Drug Design and Discovery, 14(5), 540-553. https://doi.org/10.2174/1570180813666160819125 342

38. Takahashi, K., Hashimoto, N., Nakama, C., Kamata, K., Sasaki, K., Yoshimoto, R. et al. (2009). The design and optimization of a series of 2-(pyridin-2-yl)-1Hbenzimidazole compounds as allosteric glucokinase activators. Bioorganic and Medicinal Chemistry, 17(19), 7042-7051. https://doi.org/10.1016/j.bmc.2009.05.037

39. Trott, O., and Olson, A. J. (2010). AutoDock Vina: improving the speed and accuracy of docking with a new scoring function, efficient optimization and multithreading. Journal of Computational Chemistry, 31, 455-461.

40. Tsumura, Y., Tsushima, Y., Tamura, A., Hasebe, M., Kanou, M., Kato, H. et al. (2017). TMG-123, a novel glucokinase activator, exerts durable effects on hyperglycemia without increasing triglyceride in diabetic animal models. PLoS One, 12(2), e0172252. https://doi.org/10.1371/journal.pone.0172252
41. Wang, Z., Shi, X., Zhang, H., Yu, L., Cheng, Y., Zhang, H. et al. (2017). Discovery of cycloalkylfused N-thiazol-2-yl-benzamides as tissue non-specific glucokinase activators: design, synthesis, and biological evaluation. European Journal of Medicinal Chemistry, 139, 128-152. https://doi.org/10.1016/j.ejmech.2017.07.051

42. Ye, N., Xu, X., Li, F., Ning, M., Liu, Z., Cao, Y. et al. (2012). Investigation on the oxidation of aryl oxiranylmethanols and the synthesis of 2-aryl-Nthiazolyl-oxirane-2-carboxamides as glucokinase activators. Tetrahedron Letters, 53(35), 4738-4742. https://doi.org/10.1016/j.tetlet.2012.06.111

43. Zhang, L., Chen, X., Liu, J., Zhu, Q., Leng, Y., Luo, X. et al. (2012). Discovery of novel dual-action antidiabetic agents that inhibit glycogen phosphorylase and activate glucokinase. European Journal of Medicinal Chemistry, 58, 624-639. https://doi.org/10.1016/j.ejmech.2012.06.020

44. Zhang, L., Tian, K., Li, Y., Lei, L., Qin, A., Zhang, L. et al. (2012a). Novel phenyl-urea derivatives as dualtarget ligands that can activate both GK and PPAR $\gamma$. Acta Pharmaceutica Sinica B, 2(6), 588-597. https://doi.org/10.1016/j.apsb.2012.10.002 